\title{
Electrocardiographic studies of the three-toed sloth, Bradypus variegatus
}

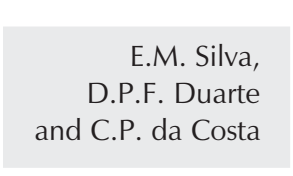

\author{
Departamento de Fisiologia e Farmacologia, \\ Universidade Federal de Pernambuco, Recife, PE, Brasil
}

\section{Correspondence \\ C.P. da Costa \\ Departamento de Fisiologia e \\ Farmacologia, UFPE \\ Av. Professor Morais Rego, $\mathrm{s} / \mathrm{n}$ \\ 50670-901 Recife, PE \\ Brasil \\ Fax: +55-81-2126-8976 \\ E-mail: cpc@ufpe.br}

Research supported by FACEPE.

Received October 29, 2004 Accepted September 14, 2005

\begin{abstract}
Electrocardiograms (ECG) obtained with standard limb leads and augmented unipolar limb leads were recorded from 17 unanesthetized adult sloths. The animals were held in their habitual position in an experimental chair. We determined heart rate and rhythm from the R$\mathrm{R}$ intervals, the amplitude and duration of each wave, and the duration of the segments and intervals of the ECG. The mean electrical axes of $\mathrm{P}$ and $\mathrm{T}$ waves and QRS complex were calculated on the basis of the amplitude of these waves in leads I, II, III, $\mathrm{aV}_{\mathrm{R}}, \mathrm{aV}_{\mathrm{L}}$, and $\mathrm{aV}_{\mathrm{F}}$. The $\mathrm{P}$ wave appeared positive in most tracings with low amplitude in lead II, the QRS complex was generally negative in leads $a V_{R}$, III and a $V_{F}$, and no arrhythmias were observed. With a mean \pm SD heart rate for all recordings of $81 \pm 18 \mathrm{bpm}$, the duration of $\mathrm{P}$ and $\mathrm{T}$ waves, QRS complex, and PR, QT and RR intervals averaged $0.05 \pm 0.02,0.15 \pm$ $0.05,0.07 \pm 0.02,0.13 \pm 0.02,0.38 \pm 0.04$, and $0.74 \pm 0.17 \mathrm{~s}$, respectively. The ECG shape had a definite configuration on each lead. The angles of the mean \pm SD electrical axes for atrial and ventricular depolarization and ventricular repolarization in the horizontal plane were $+34 \pm 68^{\circ},-35 \pm 63^{\circ}$, and $-23 \pm 68^{\circ}$, respectively. All electrical axes showed great variations and their mean values suggest that, when the sloth is in a seated position, the heart could be displaced by the diaphragm to a semi-horizontal position.
\end{abstract}

The importance of the electrocardiogram (ECG) as a tool to evaluate the electrical activity of the heart and its wide use in a variety of experimental models have led some researchers to establish standards of variation of the values of its components in different animals, such as dogs (1), rabbits (2), hamsters (3), guinea pigs $(4,5)$, cats $(6)$, and monkeys (7). Normally, the ECG is used to measure heart rate (HR). Hence, the animal being studied and the conditions under which the signal is recorded (e.g., anesthetized or unanesthetized, free ranging or tethered), can present artifacts from muscular contraction, which limits visualization and a precise analysis of the ECG signal components.

There have been some studies using the sloth ECG to quantify HR (8-14) and to identify the onset and termination of ventricular fibrillation (15).

Sloths are Eutherian mammals belonging to the order Xenarthra, family Bradypodidae. There are two genera, Choloepus and Bradypus, which have many species and can be distinguished by the number of toes (16). The Bradypus genus is widespread and found 
largely in the Northeast region of Brazil. These animals show very slow movements, a low metabolic rate, and present peculiarities in the cardiovascular system. George MarcGrave, in the 17th century, was the first to comment about the heart of these animals and to describe that, when isolated and without perfusion, it presented strong contractions (8). Wislocki, studying macro- and microanatomical aspects, cited the relatively small size of the heart when compared to other mammals with higher metabolic rates (11).

The HR of the sloth is under control of the autonomic nervous system and is lower than that recorded in other mammals of the same size (12), such as dogs (1) and rabbits (2).

The ECG of restrained and unanesthetized Bradypus variegatus was recorded by Didio (8), who could not establish an electrocardiographic pattern, due to muscular contraction interference subsequent to immobilization of the animal. After anesthesia, the interference was reduced but P- and Twave analyses were difficult to interpret.

A popular impression of the behavior of this species is that sloths spend a large part of their time suspended from tree branches, head down. In contrast, Duarte et al. (11) concluded that, in captivity, sloths (B. variegatus) spend most of their time in a sitting position in tree crotches. Thus, to make experimental conditions as natural as possible, these investigators constructed a small chair with a vertical post in the center of the seat. This chair allowed the animal to adopt its usually preferred position with little or no struggling when placed in it. In the present study, with unanesthetized sloths placed in the experimental chair, the ECG was recorded merely to quantify HR; however, it also provided good visualization of the various waves, segments and intervals.

The aim of the present study was to characterize the electrocardiographic patterns of the unanesthetized three-toed sloth, $B . v a$ - riegatus, when placed in the indicated experimental chair. Using surface electrodes to record ECG leads I, II, III, $\mathrm{aV}_{\mathrm{R}}, \mathrm{aV}_{\mathrm{L}}$, and $\mathrm{aV}_{\mathrm{F}}$, we measured the duration and amplitude of each wave, the duration of the segments and intervals, and the average values of the mean electrical atrial and ventricular axes.

ECG recordings were obtained from 17 adult sloths $(3.9 \pm 0.6 \mathrm{~kg}), 13$ males and four females. The sloths were obtained from the forest in the vicinity of Recife, PE, Brazil, and kept in the vivarium at the University for about one week for habituation to the new environment prior to being studied. In the vivarium, they were free in a large room and were given water and fresh leaves of imbauba tree (Cecropia sp.) ad libitum. During this period, body temperature and weight were measured daily, and the behavior of the animals was observed. On three different days, the animal was brought to the laboratory and placed in the experimental chair for habituation.

On the morning before the ECG recording, the animals were brought to the laboratory and shaved in four areas of the posterior surface of the trunk, where dime-size silverplate electrodes were attached with adhesive tape and held in place by a jacket. The animals were then placed in the chair and left there for about $1 \mathrm{~h}$, after which the ECG was recorded in the peripheral leads in the frontal plane (I, II, III, $\mathrm{aV}_{\mathrm{R}}, \mathrm{aV}_{\mathrm{L}}$, and $\mathrm{aV}_{\mathrm{F}}$ ) using a polygraph recorder (model 7758D System, Hewlett-Packard, Waltham, MA, USA). The polygraph was calibrated to $1 \mathrm{mV}$ per $1 \mathrm{~cm}$ vertical deflection and used at a paper speed of $25 \mathrm{~mm} / \mathrm{s}$. High-pass and low-pass filters of 1.5 and $100 \mathrm{~Hz}$, respectively, were used for signal conditioning. The ECG signals were obtained at 15-min intervals during a 2-h period, yielding eight ECG tracings for each animal. The tracing strips were organized in plates for subsequent analysis.

We determined HR and rhythm from the $\mathrm{R}-\mathrm{R}$ intervals, the amplitude and duration of 
each wave, and the duration of the segments and intervals. We also determined the mean electrical axis for atrial (ÂP) and ventricular (ÂQRS) depolarization and ventricular (ÂT) repolarization by calculating the mean polar vector and its standard deviation using the MATLAB software after converting it to the Cartesian coordinates and then projecting the resultant cardiac vector on the hexaxial system.

The experiments were carried out with previous approval of the Ethics Committee of Centro de Ciências Biológicas, Universidade Federal de Pernambuco, and with license from Instituto Brasileiro de Meio Ambiente (IBAMA, No. 013/DEVIS - 047/95 DIFAS).

The values of the ECG components for the 17 sloths are shown in Table 1. As shown in the ECG recording in Figure 1A, the P wave appeared positive in most of the tracings with low amplitude in lead II. The QRS complex was generally negative in the $\mathrm{aV}_{\mathrm{R}}$, DIII and $\mathrm{aV}_{\mathrm{F}}$ leads. HR was $81 \pm 18 \mathrm{bpm}$, with normal sinus rhythm. No arrhythmias were observed in any of the tracings analyzed $(\mathrm{N}=136)$.

According to Prosser and Brown Jr. (16), the ECG of vertebrates represents a set of waves that is similar among species, irrespective of the existence of a septum or of whether ventricular conduction is carried by the Purkinje system (mammals and birds) or by the muscle proper (heterothermic animals). The duration for the various ECG components of $B$. variegatus (Table 1 ) is longer than that obtained for other mammals of similar size, such as rabbits (2) and cats (6). This difference may be a result of the significantly higher HR found in these animals (up to $250 \mathrm{bpm}$ ) compared to the sloth (81 bpm). This view is supported by the observation that the values for sloths are similar to those found in monkeys (Table 1) (7).

Petelenz and Kosmider (2) studying rabbits, Petelenz (4) studying guinea pigs and Nara et al. (6) studying cats have demon- strated a significant percentage of abnormalities in the electrocardiographic patterns of these animals $(13,8$, and $10 \%$, respective1y). In our studies we did not observe alterations such as atrial or ventricular extrasystoles.

The PR interval (PRi) and QT interval (QTi) occupied 26 and 74\%, respectively, of the total electrical cycle at the average HR of the sloths. These percentages are similar to those of the monkey (7), a mammal whose HR is similar to that of sloths (17) and whose PRi and QTi occupy 30 and 70\%, respectively, of the electrical cycle. By contrast, the percentages of time for these intervals in sloths differ from those of the rabbit, another mammal of similar size but with a HR of 250 bpm (2) and whose PRi and QTi occupy 40 and 60\%, respectively, of the electrical cycle. These results corroborate Prosser and Brown Jr.'s (16) statement that the percentage of time occupied by the PRi and QTi in the ECG of mammals differs in relation to the HR level.

The mean electrical axis of the ventricle is an important parameter as it shows the sequence and direction of the electrical activity of the ventricular fibers, varying in human beings according to age, body type, pregnancy, posture, and ventilatory cycle (18). The mean ÂP, ÂQRS and ÂT of $B$. variegatus in the erect position are shown in

\begin{tabular}{|c|c|c|c|c|c|}
\hline \multirow[t]{2}{*}{ Parameter } & \multicolumn{4}{|c|}{ Duration (s) } & \multirow{2}{*}{$\begin{array}{l}\text { Amplitude } \\
(\mathrm{mV})\end{array}$} \\
\hline & Sloth & Cat & Rabbit & Monkey & \\
\hline$P$ wave & $0.05 \pm 0.02$ & 0.03 & 0.02 & 0.14 & $0.05 \pm 0.07$ \\
\hline PR segment & $0.07 \pm 0.02$ & - & - & - & - \\
\hline PR interval & $0.13 \pm 0.02$ & - & 0.06 & 0.15 & - \\
\hline QRS complex & $0.07 \pm 0.02$ & 0.03 & 0.02 & 0.07 & $0.07 \pm 0.33$ \\
\hline ST segment & $0.11 \pm 0.05$ & - & 0.03 & - & - \\
\hline T wave & $0.15 \pm 0.05$ & 0.10 & 0.08 & 0.29 & $0.08 \pm 0.15$ \\
\hline QT interval & $0.38 \pm 0.04$ & 0.18 & 0.16 & - & - \\
\hline RR interval & $0.74 \pm 0.17$ & 0.43 & - & - & - \\
\hline
\end{tabular}

Data for the sloth are reported as means \pm SD. 
A

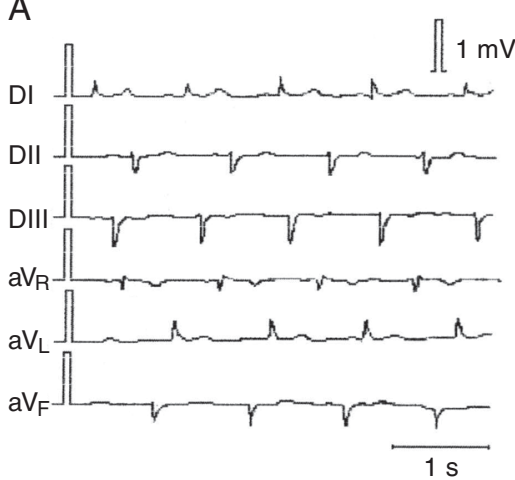

B

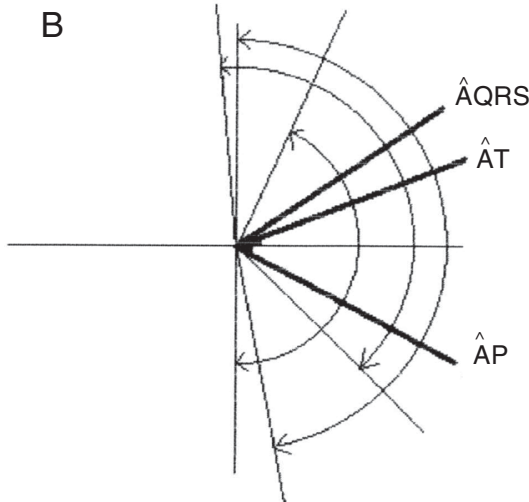

Figure 1. A, Typical electrocardiogram of the three-toed sloth, Bradypus variegatus, in the frontal leads. $B$, Directions of the mean instantaneous vectors of atrium (ÂP) and ventricle (ÂQRS) depolarization and ventricle repolarization (ÂT).

Figure 1B. The ÂP ranges from -60 to $+90^{\circ}$, with a mean of $+34 \pm 68^{\circ}$, the ÂQRS ranges from +45 to $-100^{\circ}$, with a mean value of -35 $\pm 63^{\circ}$, and the ÂT ranges from -90 to $+75^{\circ}$, with a mean of $-23 \pm 68^{\circ}$.

In cats, the ÂQR in the frontal plane presents wide variation (6), with an average projection in $+67^{\circ}$. In rabbits, Petelenz and

Kosmider (2) found ÂP ranging from $+10^{\circ}$ to $+80^{\circ}, \hat{A} Q R S$ ranging from +15 to $+100^{\circ}$ and ÂT ranging from -10 to $+80^{\circ}$. The average ÂQRS in sloths reveals a left axis deviation $\left(-35^{\circ}\right.$, Figure $\left.1 \mathrm{~B}\right)$. One possible explanation for this deviation is the large abdominal cavity of these animals in which the alimentary bolus accumulates for about 3 to 8 days before elimination as feces (19). We suggest that in the seated position in which the ECGs were recorded, the abdominal contents of the sloth would tend to displace the diaphragm upwards causing the heart to shift similarly and to produce a mean ÂQRS that indicates left axis deviation.

\section{Acknowledgments}

We thank Dr. George Ordway, Professor of Physiology, University of Texas Southwestern Medical Center, Dallas, TX, USA, for reviewing this manuscript and for helpful suggestions.

\section{References}

1. Bober S (1956). Electrocardiogram of the dog. Acta Physiologica Polonica, 7: 477-486.

2. Petelenz T \& Kosmider S (1961). Electrocardiogram of rabbits. Acta Physiologica Polonica, XII: 603-609.

3. Glassman PM \& Angelakos ET (1965). Electrocardiogram of the golden hamster. American Journal of Medical Electronics, 64: 42-44.

4. Petelenz T (1971). Electrocardiogram in the guinea pig. Acta Physiologica Polonica, XXII: 123-132.

5. Cieslar G, Sieron A, Rzepka E et al. (1986). Normal electrocardiogram in guinea pig. Acta Physiologica Polonica, 37: 139-149.

6. Nara $\mathrm{Y}$, Morohoshi $\mathrm{Y}$, Ikeda $\mathrm{N}$ et al. (1986). The electrocardiogram of unanesthetized cats fixed in a net. Jikken Dobutsu, 35: 21-28.

7. Toback JM, Clark JC \& Moorman WJ (1978). The electrocardiogram of Macaca fascicularis. Laboratory Animal Science, 28: 182-185.

8. Didio LJA (1968). Myocardial ultrastructure and electrocardiograms of the sloth (Bradypus tridactylus) under normal and experimental conditions. Journal of Morphology, 124: 83-104.

9. Oliveira LHA, Da Costa CP \& Huggins SE (1980). Cardiac mass, blood temperature and ventricular fibrillation: a study of the comparative physiology of the three toed sloth and domestic cat. Comparative Biochemistry and Physiology. Part A, 67: 483-490.

10. Cabral AMS, Da Costa CP \& Huggins SE (1980). Cardiac output in the three toed sloth, Bradypus tridactylus. Comparative Biochemistry and Physiology. Part A, 67: 527-530.

11. Duarte DPF, Da Costa CP \& Huggins SE (1982). The effects of posture on blood pressure and heart rate in the three-toed sloth.
Comparative Biochemistry and Physiology. Part A, 73: 697-702.

12. Duarte DPF, Da Costa CP \& Huggins SE (1983). The autonomic component in blood pressure and heart rate effects of tilting in the three toed sloth. Comparative Biochemistry and Physiology. Part C, 74: 485-492.

13. Moura Filho AG, Huggins SE \& Lins SG (1983). Sleep and waking in the three-toed sloth, Bradypus tridactylus. Comparative Biochemistry and Physiology. Part A, 76: 345-355.

14. Valentinuzzi ME, Ruiz EV \& Da Costa CP (1984). Ventricular fibrillation threshold in the three-toed sloth (Bradypus tridactylus). Acta Physiologica et Pharmacologica Latino-Americana, 34: 312-322.

15. Wetzel RM \& Ávila-Pires FD (1980). Identification and distribution of the recent sloths in Brazil (Edentata). Revista Brasileira de Biologia, 40: 831-836.

16. Prosser CL \& Brown Jr FA (1975). Comparative Physiology. W.B. Saunders Co., Philadelphia, PA, USA.

17. Anderson ST, Downs WG, Lander P et al. (1992). Advanced Electrocardiography. Space Labs, Inc., Washington, DC, USA.

18. Montgomery GG \& Sunquist M (1975). Impact of sloths on neotropical forest flow and nutrient cycling. In: Golley FB \& Medina E (Editors). Tropical Ecological Systems. Trends in Terrestrial and Aquatic Research. Spring-Verlag, New York, 69-98.

19. Ayala I, Gutierrez C, Benedito JL et al. (1999). Morphology and amplitude values of the $P$ and $T$ waves in the electrocardiograms of Spanish-bred horses of different ages. Zentralblatt für Veterinarmedizin. Reihe A, 46: 225-230. 